\title{
STUDI TAKHRIJ HADIS \\ ANAK ITU PENYEBAB AKHLAK BURUK ORANG TUA
}

\author{
DARSITUN \\ State Institute on Islamic Studies Purwokerto \\ Central Java, Indonesia \\ Email: masdar1982@gmail.com
}

\section{Abstrak}

This research is motivated by the case that children are often lead to the break up of a family. Such great attention to the child in the form of wrong actions becomes a trigger such as over-treatment in facilitating children's needs, excessive worries and so on. To find out how the Messenger of Allāh gave guidance in dealing with the child, a study of the hadiths related to the theme was carried out. Using a literature study, this article found that there are several traditions that talk about the presence of children in the family. And this article concludes that the child can be the cause of the appearance of bad characters in parents such as majbanatun, mabkhalatun, mahzanatun and majhalatun.

\section{Keywords}

Hadis, Fitnah Anak, Karakter Buruk Orang Tua

\section{Pendahuluan}

Pendidikan Anak merupakan masalah yang amat penting untuk dilaksanakan dengan sebaik-baiknya. Hal ini disebabkan karena anak menduduki posisi yang sangat penting dalam kehidupan, baik dalam keluarga maupun dalam kehidupan masyarakat. Anak merupakan generasi pelanjut dari satu generasi. Alquran sendiri memberikan kedudukan yang amat penting dalam kehidupan anak dengan berbagai istilah yang digunakan. Anak dalam Islam memiliki kedudukan yang penting dan cukup mendapatkan perhatian bahkan dalam 
beberapa ayat disebutkan sebagai perhiasan kehidupan dunia (QS. 20:131) dan fitnah (QS. 64:14-15). Anak-anak digambarkan sebagai perhiasan, yakni sesuatu yang sangat berharga sehingga membutuhkan perlindungan dan pemeliharaan yang sungguh-sungguh. Anak merupakan generasi pelanjut dari satu generasi. Alquran sendiri memberikan kedudukan yang amat penting dalam kehidupan anak dengan berbagai istilah yang digunakan.

Abdullah Nashih Ulwan mengatakan, bahwa dalam hati orang tua akan tumbuh perasaan cinta terhadap anak dan tumbuh pula perasaan-perasaan psikologis lainnya, berupa perasaan kebapakan dan keibuan untuk memelihara, mengasihi,, menyayangi dan memperhatikan anak. ${ }^{1}$ Tidak ada yang menyangkal, bahwa anak akan tumbuh dengan iman yang benar, berhiaskan diri dengan etika Islami, bahkan sampai pada puncak nilai-nilai spiritual yang tinggi, dan kepribadian utama, jika ia hidup dan dibekali dengan dua faktor yaitu pendidikan Islami yang utama dan lingkungan yang baik. ${ }^{2}$

Firman Allah dalam surat At Taghabun ayat 14-15 menunjukkan dengan sangat tegas menandaskan, anak bisa menjadi fitnah dunia bagi kita. Ibarat permata Zamrud yang wajib kita pelihara. Maka berhati-hatilah, janganlah kita terlena dan tertipu sehingga kita melanggar perintah Allah SWT dan menodai larangan-Nya. ${ }^{3}$ Anak juga dikatakan sebagai fitnah

1 Abdullah Nashih Ulwan, Tarbiyah al-Aulad fi al-Islam, diterjemahkan dengan judul "Pendidikan Anak Dalam Islam" (Jakarta: Pustaka Amani, 2007), hal. 27.

${ }^{2}$ Abdullah Nashih Ulwan, hal. 185-86.

3 Admin, "Buah Hati, Antara Perhiasan Dan Ujian Keimanan - Almanhaj Media Salafiyyah Ahlus Sunnah," diakses 1 Mei 2019, https://almanhaj.or.id/3032-buah-hati-antara-perhiasan-dan-ujiankeimanan.html.

TAHDIS Volume 10 Nomor 1 Tahun 2019 
sebagaimana hadis yang disampaikan oleh Sahabat Hudzaifah bin Yaman, ia berkata, Rasulullah SAW bersabda:

Artinya:

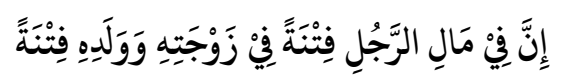

"Sesungguhnya di dalam harta seseorang ada fitnah, demikian pula pada istri dan anaknya terdapat fitnah". ${ }^{4}$

Imam al Munawi menjelaskan hadis tersebut di atas bahwa seseorang yang kaya raya lagi memiliki harta itu ujian, fitnah dan musibah. Demikian juga pada istri dan anaknya merupakan fitnah. Sebagaimana dijelaskan dalam Alquran dalam banyak ayat. Nasehat dari Rasulullah SAW tersebut merupakan sesuatu yang dihasilkan dari pengalaman yang dialami beliau SAW. Banyak fakta mengungkap kebenaran hadis ini bahwa sungguh mereka yang disebutkan dalam hadis benar-benar akan terjerumus ke dalam dosa, permusuhan dan terkadang juga mendekatkan orang-orang di sekitarnya untuk mendekat kepada Allah SWT. 5

Abdullah bin Abbas ketika menjelaskan ayat :

Artinya:

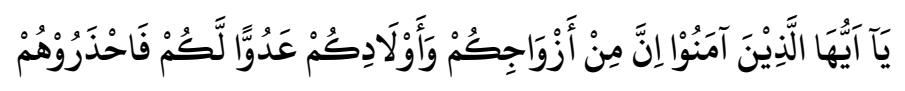

Hai orang-orang yang beriman! Sesungguhnya diantara istri-istri kalian dan anak-anak kalian ada yang menjadi musuh bagi kalian, maka berhati-hatilah (waspadalah) terhadapnya. (QS. At Taghabun : 14)

\footnotetext{
4 Imam Al Munawi, "Faidhul Qadir Syarhul Jami'ush Shaghir, Juz II Hadis Nomer 2236," accessed March 20, 2019 https://books.google.co.id/books 5 Imam Al Munawi.
} 
Yang dimaksud 'musuh bagi kalian' yaitu mereka orangorang yang telah masuk Islam dari kalangan ahli Makkah yang menginginkan untuk bertemu nabi SAW namun mereka enggan untuk meninggalkan istri dan anak-anak mereka barang sebentar dengan berbagai alasan yang dibuat-buat. Kemudian ketika orang-orang sudah berdatangan lebih dahulu untuk berhijrah, orang-orang tadi baru bermunculan dan menemui nabi dengan mengemukakan alasan-alasan mereka akan ketidakhadirannya. Dan mereka pun akhirnya menyesal karena perbuatan keliru yang mereka lakukan, sambil mengumpat saat melihat kaum muslimin telah dahulu memahami ilmu dan agama ini daripada mereka lalu mereka pulang dengan niat akan memberikan hukuman terhadap anak dan istri mereka padahal mereka sendiri yang telah terfitnah. ${ }^{6}$

Berbeda dengan Ibnu Katsir, dalam kesempatan yang lain Asy Syinqithy ${ }^{7}$ saat menjelaskan ayat berikut ini:

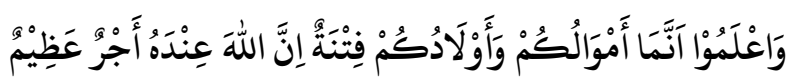

Artinya:

"Dan ketahuilah bahwasanya harta dan anak kalian itu adalah fitnah, dan sungguh disisi Allah pahala yang besar".8

Bahwa dalam ayat tersebut Allah memerintahkan manusia agar mengetahui dengan yakin bahwa harta dan anakanak mereka itu merupakan sebuah ujian yang akan selalu

\footnotetext{
6 Ibnu Katsir, “Tafsir Ibnu Katsir,” diakses 5 April 2019, http://quran.ksu.edu.sa/tafseer/katheer/sura64-aya14.html.

7 Mukhtar Asy Syinqithy, "Tafsir Adhwaul Bayan," diakses 5 April 2019, https://www.islamweb.net/newlibrary

8 Admin, "Surat Al-Anfal Ayat 28 Arab, Latin, Terjemahan Arti Bahasa Indonesia," diakses 21 Maret 2019, https://tafsirweb.com/2894-surat-alanfal-ayat-28.html.
}

TAHDIS Volume 10 Nomor 1 Tahun 2019 
menjadi jamuan hari-hari mereka di dunia. Sebuah pertanyaan yang patut direnungkan apakah keberadaan harta dan anakanak tersebut membawanya pada keadaan yang di ridhai Allah SWT? Bahkan Allah menambahkan dalam ayat lain bahwa istriistri para suami juga menjadi fitnah. Maka fitnah itu bisa terjadi pada tiga perkara harta, anak, dan istri.

Sebagai contoh harta dan anak, keduanya menjadi perkara yang harus diwaspadai oleh manusia supaya tidak terjerumus ke dalam fitnah yang ada di dalamnya berupa tenggelam dalam perkara yang tidak diridhoi Allah. Allah juga memerintahkan manusia untuk menelaah atas perkara yang dibenci dari musuh-musuh yang begitu dekat dan akrab di sekeliling manusia. Sebagai konklusinya, Asy Syinqithy menyimpulkan bahwa terdapat larangan bagi orang yang beriman agar tidak terlena dengan kesibukan hatinya atas harta dan anak dari mengingat Allah SWT. ${ }^{9}$

Jika demikian, maka harta yang seperti apa yang menyebabkan manusia terfitnah dengannya? Anak-anak yang seperti apa yang menyebabkan manusia terfitnah dengannya? Istri yang seperti apa yang menyebabkan manusia terfitnah? Dan jika mereka bermaksiat kepada Allah apa yang perlu dilakukan? Kajian ini insya Allah akan memfokuskan pembahasan tentang Fitnah Anak secara gamblang dan tuntas berdasarkan hadis-hadis nabi SAW.

\section{Anak dalam Pandangan Islam}

Anak dalam bahasa Alquran terkadang disebutkan dengan walad (ولد), kadang disebutkan dengan kata banin (بنين) dan bentukannya. Masyarakat hari ini sering menganggap sama keduanya, disisi lain banyak pula memahaminya dengan

${ }^{9}$ Mukhtar Asy Syinqithy, "Tafsir Adhwaul Bayan." 
persepsi yang keliru. Mereka menyangka banin itu meliputi laki-laki dan perempuan. Sedangkan walad dimutlakkan dengan laki-laki saja.

Padahal dalam istilah bahasa arab terdapat perbedaan yang jelas. Kata banin itu meliputi anak laki-laki, untuk perempuan menggunakan banat (بنات). Bentuk tunggal dari banin adalah ibnun (ابن), sedangkan banat bentuk tunggalnya adalah ibnatun (ابنة).10

Allah SWT menyatakan:

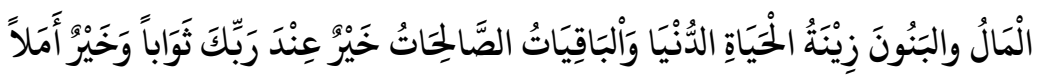
Artinya:

"Harta dan anak-anak adalah perhiasan kehidupan dunia tetapi amalan-amalan yang kekal lagi saleh adalah lebih baik pahalanya di sisi Tuhanmu serta lebih baik untuk menjadi harapan".11

Demikian juga dalam ayat lain,

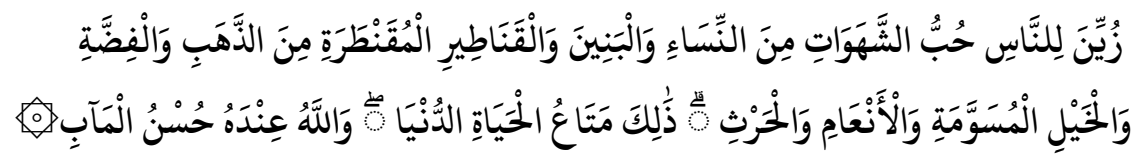
Artinya:

"Dijadikan indah pada (pandangan) manusia kecintaan kepada apa-apa yang diingini, yaitu: wanita-wanita, anak-anak, harta yang banyak dari jenis emas, perak,

10 Almaany Team, " تعريف و شرح و معنى بنون بالعربي في معاجم اللغة العربية معجم المعاني الجامع

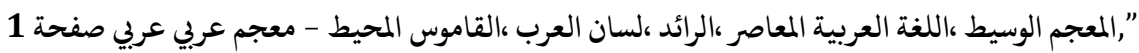
diakses 21 Maret 2019, https://www.almaany.com/ar/dict/ar-

11 "Surat Al-Kahfi Ayat 46 Arab, Latin, Terjemahan Arti Bahasa Indonesia," diakses 21 Maret 2019, https://tafsirweb.com/4872-surat-al-kahfi-ayat46.html.

TAHDIS Volume 10 Nomor 1 Tahun 2019 
kuda pilihan, binatang-binatang ternak dan sawah ladang. Itulah kesenangan hidup di dunia, dan di sisi Allah-lah tempat kembali yang baik (surga)".12

\section{Pentingnya Pendidikan Anak dalam Islam}

Anak-anak adalah generasi penerus yang akan datang bagi ummat Islam. Memberikan perhatian terhadap pendidikan masa depan untuk mereka, mengajari mereka merupakan komponen terpenting bagi estafet perputaran kehidupan. Pendidikan ini kewajiban bagi setiap muslim yang memiliki keyakinan beriman kepada Allah dan Hari Akhir.

Ibnu Katsir saat menjelaskan ayat berikut ini,

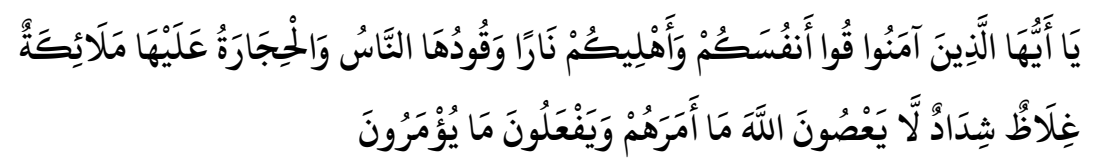

Artinya:

"Hai orang-orang yang beriman, peliharalah dirimu dan keluargamu dari api neraka yang bahan bakarnya adalah manusia dan batu; penjaganya malaikat-malaikat yang kasar, yang keras, yang tidak mendurhakai Allah terhadap apa yang diperintahkan-Nya kepada mereka dan selalu mengerjakan apa yang diperintahkan."13

Beliau telah memberikan penjabaran detail akan hal ini. Beliau mengatakan bahwa ayat tersebut mengandung nasehat yang agung dan teguran agar menghindari bahaya siksa neraka.

\footnotetext{
12 "Surat Ali 'Imran Ayat 14 Arab, Latin, Terjemahan Arti Bahasa Indonesia," diakses 21 Maret 2019, https://tafsirweb.com/1146-surat-ali-imran-ayat14.html.

13 Ibnu Katsir, “Tafsir Surat At-Tahrim, ayat 6-8," diakses 9 April 2019, http://www.ibnukatsironline.com/2015/10/tafsir-surat-at-tahrim-ayat-68.html.
} 
Beliau menukil ucapan Qatadah maksud ayat tersebut adalah engkau memerintahkan keluargamu agar menaati Allah SWT dan melarang mereka bermaksiat kepada Allah, Engkau memberikan contoh keteladanan untuk mereka agar diikuti dan dicontoh, dan engkau membantu mereka untuk meraih keteladanan tersebut. Maka jika engkau melihat ada kemaksiatan yang dilakukan mereka terhadap Allah, yang itu mengundang murka Allah dan azab dari Allah, engkau segera menegur mereka dan memberikan pembinaan, demikian seterusnya. ${ }^{14}$

Bahkan Adh Dhahak, salah seorang Tabi'in pernah mengomentari ayat tersebut dengan pernyataan Hak seorang muslim adalah hendaknya ia mengetahui dan mengajarkan keluarganya, kerabatnya, budaknya apa-apa yang diwajibkan Allah Ta'ala kepada mereka tentang akidah, ibadah dan akhlak juga muamalah. Dan juga melarang mereka dari perbuatan yang mengundang murka Allah SWT.

Dalam beberapa kesempatan, Rasulullah SAW juga telah menjelaskan dengan gamblang perihal tanggung jawab kepemimpinan dalam rumah tangga ini dan tugas untuk melaksanakan amanat yang dipikul. Dalam sebuah hadis yang diriwayatkan oleh Abdullah bin Umar RA bahwasanya Nabi SAW bersabda:

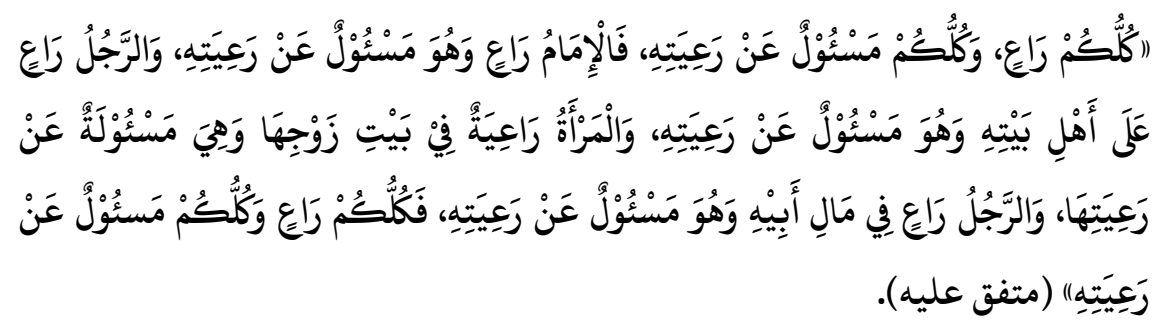

Artinya:

14 Ibnu Katsir.

TAHDIS Volume 10 Nomor 1 Tahun 2019 
"Ketahuilah setiap kalian adalah pemimpin, dan setiap kalian akan dimintai pertanggungjawaban atas yang dipimpin, penguasa yang memimpin manusia dia akan dimintai pertanggungjawaban atas yang dipimpinnya, seorang lelaki (kepala keluarga) adalah pemimpin keluarganya dan dia dimintai pertanggungjawaban atas yang dipimpinnya, dan seorang perempuan (istri) adalah pemimpin terhadap keluarga rumah suaminya dan juga anak-anaknya dan dia akan dimintai pertanggungjawaban atas kepemimpinannya, dan budak juga pemimpin terhadap harta tuannya dan akan dimintai pertanggung jawaban terhadapnya. Ketahuilah, setiap kalian adalah bertanggung jawab atas yang dipimpinnya."15

Oleh karena itu perkara yang terpenting dalam hal ini yaitu memberi perhatian penuh dengan ilmu dalam melakukan pekerjaan mendidik anak, memahamkan mereka tentang agama Islam ini dengan baik sehingga Islam akan semakin indah dipandang saat generasinya berada di atas jalan yang lurus. Dalam proses perkembangan anak, terdapat suatu fase yang dikenal dengan fase imitasi. Pada fase ini, seorang anak selalu meniru dan mencontoh orang-orang dewasa di sekitarnya, terutama orang tuanya atau gurunya. Metode keteladanan ini sangat cocok diterapkan pada fase ini. Dalam pendidikan, pendidik (orang tua dan guru) tidak cukup hanya dengan memberi nasehat dalam arti menyuruh, tetapi seharusnya memberikan teladan. Misalnya; menyuruh anak ke masjid, sementara dia tidak pernah ke mesjid. Tidak satunya kata dan perbuatan, menjadikan orang tua/guru tidak memiliki

15 Admin, "Takhrij Hadits Kullukum Ra'in," diakses 9 April 2019, https://library.islamweb.net/hadith

TAHDIS Volume 10 Nomor 1 Tahun 2019 
wibawa sebagai pendidik, dan menjadikan anak bingung, karena apa yang dilihatnya tidak sesuai dengan apa yang didengarnya.

Imam Al Munawi ketika menafsirkan ayat di atas hendaknya seorang ayah mengajari adab kepada anaknya saat sudah baligh, berakal yang mana keadaan tersebut memungkinkan bagi si anak untuk berkembang dan menumbuhkan akhlak pada dirinya dengan akhlak yang saleh, mulia sebagaimana dilakukan oleh kaum muslimin. Seorang pemimpin rumah tangga selalu berusaha untuk menjaga anak dan istrinya dari terkontaminasi akhlak yang merusak, mengajarkan pada mereka Alquran Alkarim, adab dan sunahsunah kebaikan yang telah dicontohkan oleh nabi SAW. Semua itu akan menjadi sebab para orang tua diselamatkan dari siksa dan azab neraka. ${ }^{16}$

\section{Manfaat Mendidik Anak}

Tidak ada sesuatu yang lebih berharga daripada pendidikan anak dalam kacamata pendidikan Islam. Hal itu disebabkan anak adalah tidak semata-mata investasi dunia saja namun juga investasi akhirat. Para orang tua akan banyak merasakan faedah atas keberadaan anak di tengah mereka. Di antara manfaat itu adalah ;

a. Para orang tua dapat berperan menjadi penunjuk arah bagi anak-anaknya dalam melakukan kebaikan. Dan pahala yang besar bagi penunjuk kebaikan adalah memperoleh besaran pahala yang sama dengan pelaku kebaikan itu sendiri sebagaimana dalam hadis Anas Bin Malik RA. ${ }^{17}$

\footnotetext{
16 Al Munawi, Faidhul Qadir Syarhul Jamiush Shaghir min Ahaditsul Basyiri Nadzir Juz 3 (Dar Al Kotob Al Ilmiyah, 2018).

17 At Tirmidzi, Sunan At Tirmidzi hadits no. 2670, t.t.
}

TAHDIS Volume 10 Nomor 1 Tahun 2019 
b. Doa-doa yang dilantunkan oleh anak-anak yang saleh sebesar-besar keuntungan bagi para orang tua saat kematian menjemputnya. Sungguh sangat rugi orang tua yang tidak memiliki anak keturunan yang saleh sebagaimana diriwayatkan dalam hadis Abu Hurairah RA. ${ }^{18}$

c. Lantunan istighfar (permohonan ampunan) yang keluar dari mulut anak-anak yang saleh untuk kedua orang tuanya akan mengangkat derajat kedudukan para orang tua di surga. Dari Abu Hurairah RA berkata; Rasulullah bersabda:

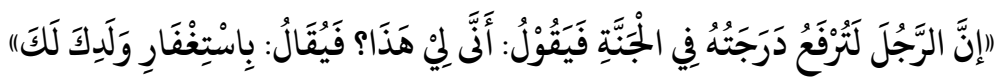
Artinya:

"Sesungguhnya seseorang itu benar -benar akan terangkat derajatnya di surga. Lalu orang itu berkata kenapa bisa begini? Disahutlah keheranannya itu dengan suara : itu terjadi karena sebab istighfar-nya anakmu kepada Allah untukmu."19

Termasuk rahmat Allah SWT adalah Dia menjadikan banyak sebab untuk mengangkat derajat kedudukan hamba-Nya dan mengampuni dosa-dosa. Diantaranya Allah menjadikan beristighfar-nya seorang anak untuk kedua orang tuanya sebagai sebab diangkat derajat kedua orang tuanya di surga. Sebagaimana dikatakan dalam hadis di atas. Makna tersiratnya bahwa kedua orang tua akan ditambahkan derajat kemuliaannya di surga tanpa sebab satu pun dari amal perbuatan mereka sendiri, namun pendidikan dan kebaikan anak terhadap keduanya itulah

18 Imam Muslim, Shahih Muslim Hadits no. 1613, t.t.

19 Ibnu Majah, “Sunan Ibnu Majah, Kitabul Adab Juz 1,” diakses 1 Mei 2019, https://library.islamweb.net/NewLibrary/display_book.php?bk_no=54\&ID $=1406 \&$ idfrom $=6702 \&$ idto $=7018 \&$ bookid $=54 \&$ startno $=3$. 
yang mengantarkan mereka kepada posisi yang dimuliakan Allah SWT.

d. Memperbaiki pendidikan anak menjadi sebab seseorang dimasukkan ke dalam surga. Dari Aisyah Ummul Mukminin RA berkata ; Rasulullah SAW bersabda : Barang siapa yang diuji masalah yang terjadi pada anak perempuannya, lalu ia bersabar atas ujian tersebut, maka ia akan terlindungi dari panasnya api neraka. (HR. At Tirmidzi :1913)

e. Jika dianalisis cuplikan dan simpulan dari beberapa hadis yang penulis utarakan di atas dapat mengerucut pada kesimpulan betapa bermanfaat aktivitas mendidik anak itu bagi orang tua. Betapa pentingnya memberikan perhatian atas pendidikan agama untuk anak keturunannya. Sehingga anjuran yang agung ini, selalu memotivasi para orang tua yang ingin dan rindu dengan kampung surga bahkan bertetangga dengan nabi SAW.

\section{Teks Hadis}

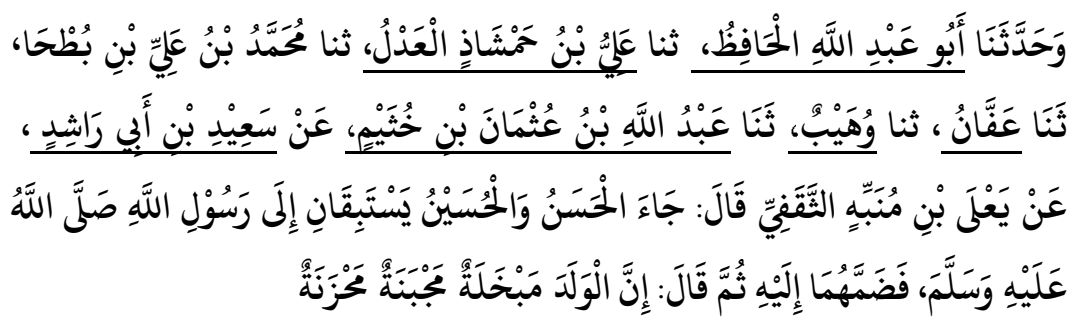

\section{Takhrij Hadis}

1. Imam Al Baihaqi meriwayatkan hadis ini dalam kitab As Sunanul Kabir hadis ke 19173.20

20 Al Baihaqy, “As Sunanul Kabiir," diakses 21 Maret 2019, http://www.hadithportal.com

TAHDIS Volume 10 Nomor 1 Tahun 2019 
2. Imam Al Bukhari ${ }^{21}$ membuat sebuah bab dengan judul babul walad mabkhalatun majbanatun ( باب الولد مبخلة (مجبنة).

3. Imam Al Hakim juga meriwayatkan hadis ini dalam kitab Al Mustadrak 22

4. Imam Al Mawardi juga meriwayatkan hadis ini dalam kitab Adabud Dunya wad Diin. ${ }^{23}$

5. Al Qadhi bin 'Iyadh juga meriwayatkan hadis ini dalam kitab Ikmalul Mu'allim 'ala Shahih Muslim. ${ }^{24}$

6. Imam Ath Thabrani meriwayatkan hadis ini dalam kitabnya juga. 25

7. Ibnu Majah meriwayatkannya dalam Shahihnya. ${ }^{26}$

\section{Terjemahan Hadis}

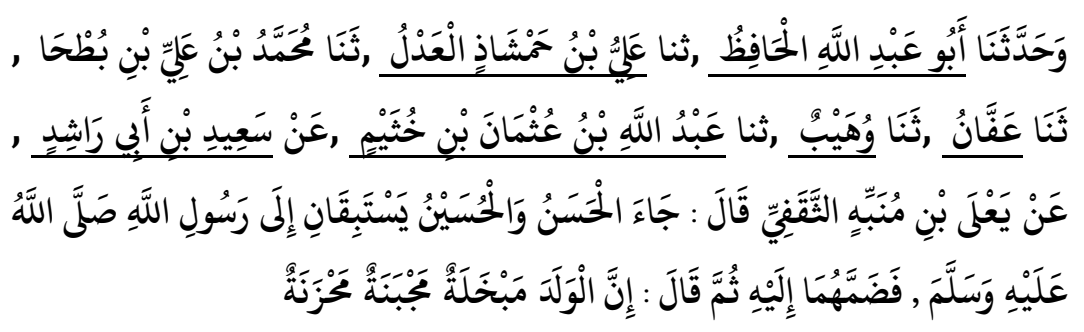

Artinya:

"Berkata kepada kami Abu Abdillah Al Hafidz, menceritakan kepada kami Ali bin Hamsyadz al 'Adil, menceritakan kepada kami Muhammad bi Ali bin Buthha,

21 Kitab Adabul Mufrad, Al Bukhari, “فصل: بَابُ الْوَلَُُ مَبْخَلَةُ مَجْبَنَةُّنداء الإِيمان, diakses 21 Maret 2019, http://www.al-eman.com

22 IslamKotob, المستدرك على الصحيحين ـ للحاكم ـ الفهارس/(IslamKotob, t.t.).

23 IslamKotob, أدب الدنبا والدين(IslamKotob, t.t.).

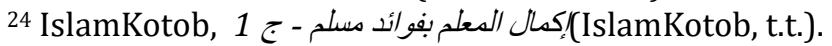

25 Jalaluddin As Suyuti, Yusuf An NAbhani, Muhammad Nashiruddin Al Albani, Tartib Ahadits Shahih Al Jami Ash Shaghir wa ziyadatuhu 'alal abwabil fiqhiyah (Maktabat al-ma"arif, 1986).

26 Admin, "Ad Durarus Saniyah - Al Muasu'ah al haditsiyah," diakses 20 Juni 2019, https://www.dorar.net/hadith/search

TAHDIS Volume 10 Nomor 1 Tahun 2019 
menceritakan kepada kami 'Affan, menceritakan kepada kami Wuhaib, menceritakan kepada kami Abdullah bin Utsman bin Khutsaim, dari Sa'id bin Abi Rasyid, dari Ya'la bin Munabbih Ats Tsaqafy berkata: Al hasan dan Al Husain datang menemui Rasulullah SAW sambil berlarian, kemudian Rasulullah SAW menggendong keduanya, lalu beliau SAW bersabda : Sesungguhnya anak itu menjadi alat orang tua berbuat bakhil, pengecut dan penakut."

\section{Pelajaran yang Dapat Dipetik dari Hadis Ini}

Dari matan hadis di atas dapat diambil beberapa pelajaran yaitu ;

1. Anak dan keturunannya termasuk nikmat Allah yang diberikan kepada para hamba-Nya. Akan tetapi sebagian orang tidak berupaya memperbaiki hubungan dan muamalah mereka terhadap nikmat Allah yang agung ini. Demikian pula usaha-usaha untuk menghindari terjadinya fitnah anak dan siksaan Allah yang disebabkan oleh anaknya. Padahal Rasulullah SAW telah mengingatkan hal tersebut.

2. Dalam matan yang lain dijelaskan oleh Ya'la Al 'Amiry Radhiyallohu 'anhu- : Al Hasan dan Al Husain keduanya berlari, maksudnya saling berlomba lari, sedangkan menuju Rasulullah SAW kemudian beliau menggendong keduanya. Lalu bersabda : Sesungguhnya anak itu adalah mabkhalatun (مبخلة)maksudnya adalah salah satu sebab menjadi bakhil dengan harta yang dimiliki, majbanatun (مجبنة) maksudnya salah satu sebab orang tua menjadi pengecut, hal itu terjadi saat orang tua lelbih menyukai duduk-duduk menghindari perang karena khawatir kalau dia ikut perang kemudian dirinya 
meninggal dunia, maka anak-anaknya akan ikut siapa? Siapa yang memikirkan keberlangsungan hidupnya, bahkan hal itu menjadikan munculnya rasa takut akan kematian yang menimpanya padahal kematian itu pasti akan dialaminya suatu saat nanti.

3. Ucapan nabi SAW di atas merupakan kinayah atas perilaku sebagian orang yang lebih mencintai anak keturunannya daripada resiko yang dialami, sebab hal itu akan menjadi terpuji. Sekalipun secara dzahir hadis, mengandung makna tersirat dan sindiran tentang tercelanya orang yang menyibukkan dirinya dengan anak dan keturunannya. Rasulullah SAW menyebutkan keduanya (Al Hasan dan Al Husain) dalam hadis ini karena keduanya adalah cucu Rasulullah SAW dimana rasulullah menampakkan kecintaan beliau dari sisi manusiawi. Dan kecintaan yang berlebihan akan mewariskan karakter buruk seperti sifat bakhil dan pengecut bagi orang yang belum mampu meraih derajat penghambaan yang benar terhadap Allah SWT dan juga konsekuensinya yakni mendahulukan kecintaan dan keridhaan Allah di atas yang lain karena Allah, hanya Dialah Zat yang layak dicintai secara hakiki. Sedangkan selain Allah SWT adalah sesuatu yang diperbolehkan untuk dicintai namun sifatnya hanya idhofi (اضافي).

4. Dijelaskan dalam riwayat Ath Thabrani ada tambahan lafadzh matan yaitu majhalatan (مجهلة)maksudnya anak itu bisa menjadi satu sebab bodohnya orang tua terhadap ilmu agama karena keberadaan anak itu selalu menariknya untuk melakukan refreshing, jalan-jalan, bertamasya dan mengundang untuk memberikan hiburan dan kesenangan bagi anak-anaknya ke tempattempat wisata. Hal ini akan menyebabkan keberadaan 
anak itu sebagai sebab orang tua meninggalkan dari rihlah (perjalanan) menuntut ilmu dan usaha yang sungguh-sungguh dalam memperoleh ilmu tersebut. Sebagai dampaknya orang tua lebih bersemangat dalam mencari nafkah harta demi memberikan kepuasan terhadap buah hatinya.

5. Dalam riwayat Ahmad, dari jalur Al Asy'ab bin Qais radhiyallohu 'anhu- ada tambahan lafadz 'mahzanatan' (محزنة)karena anak itu akan menggiring kedua orang tua kepada suasana bersedih hati. Terkadang anak itu sakit maka orang tuanya akan ikut bersedih hatinya, jika anaknya meminta sesuatu namun belum bisa memenuhinya maka orang tua akan larut dalam kesedihan. Maksud ini semuanya adalah bahwa anak-anak itu merupakan jalan prasangka karena keberadaannya menjadi sebab terjadinya perkaraperkara di atas yang menimpa para orang tua. Maka berhati-hatilah terjerumus ke dalam fitnah anak ini. Karena dari jalur yang lain terdapat banyak hadis yang menunjukkan keutamaan mendidik anak dan besarnya pahala dalam mendidik anak.

6. Dalam hadis ini juga terdapat peringatan agar setiap orang tua mewaspadai fitnah anak-anak ini karena keberadaannya dapat menjadi sebab para orang tua menjauh dari ketaatan dan tidak melaksanakan kewajiban kepada Allah SWT.

Ibu bapak merupakan orang yang paling bertanggung jawab terhadap pendidikan anak-anak, terutama ketika anak masih berada pada fase perkembangan di mana mereka sangat membutuhkan perhatian dan bimbingan, yakni pada masa anak dan masa pubertas, karena pada masa ini, seorang anak akan mengalami masa kegoncangan kejiwaan. Pada fase ini, seorang 
anak sangat membutuhkan bimbingan dan perhatian dari orang-orang dewasa disekitarnya, terutama orang tuanya.

Dengan perhatian yang senantiasa diberikan kepada anak, anak akan selalu merasakan betapa orang tua/gurunya menyayanginya, sehingga jika anak melakukan perbuatan yang baik, sang anak akan mendapatkan hadiah, walaupun hanya dengan mimik. Demikian pula jika ia melakukan suatu kesalahan, ia akan memperoleh hukuman, sekalipun hanya dengan mimik saja. Hal ini akan sangat berpengaruh dalam kehidupan anak. Perhatian yang diberikan merupakan kebutuhan rohaniah yang tidak bisa digantikan dengan materi, sebab materi adalah kebutuhan jasmaniah, dan tidak dapat ditukar satu dengan yang lain. Dengan demikian, maka perhatian merupakan salah satu metode pendidikan dalam Islam.

Selanjutnya, anak-anak yang menjadi fitnah bagi kedua orang tuanya. Pun dengan anak-anak yang dikaruniakan kepadanya. Mereka menjadi cobaan bagi orang tuanya ketika tidak diberi pendidikan soal akidah dan kehidupan yang hakiki di akhirat kelak. Akhirnya, anak-anak itu tumbuh dengan fisik yang membanggakan, tapi amat mengkhawatirkan kualitas akhlak dan agamanya. Fitnah ialah ujian yang bisa menyelamatkan atau menjerumuskan. Seorang anak sebagai fitnah memiliki potensi mengangkat derajat orang tuanya, atau menenggelamkan keduanya di dasar lembah neraka dengan segala siksanya. Anak-anak juga berpotensi menjadi ujian yang mengantarkan kepada keburukan ketika semua inginnya diikuti.

Bahkan, orang tua tidak segan-segan menggadaikan kehormatannya dengan memakan harta yang haram demi menuruti keinginan nafsu anak-anaknya. Bukankah ada begitu 
banyak orang tua yang melakukan korupsi dan mengupayakan harta haram dengan dalih menyayangi anaknya?

Ketika rasa sayang pada anak kemudian melalaikannya dari ibadah. Ketika rasa sayang pada anak kemudian membuatnya meninggalkan perintah Allah. Tidak perlu berpikir jauh, meninggalkan perintah Allah dapat berbentuk macam-macam, mulai dari yang berkaitan dengan materi hingga non materi. Seorang pedagang kemudian berbuat curang dengan timbangannya agar mendapat keuntungan lebih dan dapat membelikan mainan untuk anaknya. Ada lagi seorang ayah yang lebih mengikuti keinginan anaknya pergi ke tempat wisata, sementara sang ibu tengah menunggu untuk dikunjungi. Ketika rasa sayang kemudian justru mengundang murka Allah, maka Allah pun memberikan peringatan.

Allah SWT berfirman:

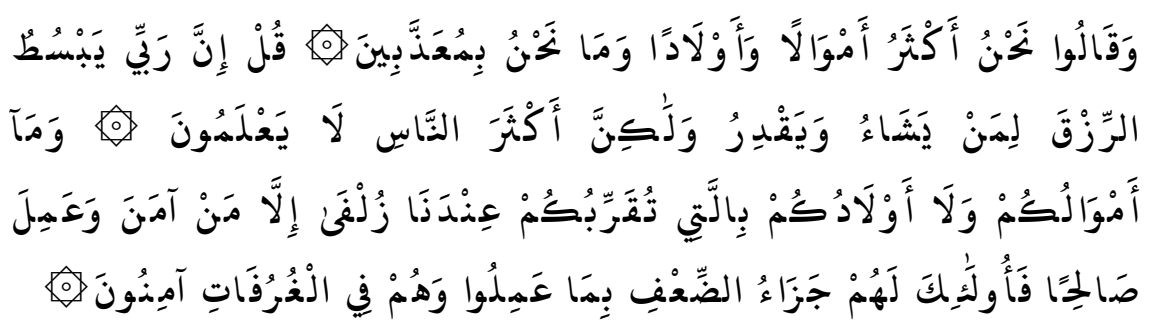
Artinya:

"Dan mereka berkata: "Kami lebih banyak mempunyai harta dan anak-anak (daripada kamu) dan kami sekalikali tidak akan diazab." Katakanlah, "Sesungguhnya Tuhanku melapangkan rezeki bagi siapa yang di kehendaki-Nya dan menyempitkan (bagi siapa yang dikehendaki-Nya), akan tetapi kebanyakan manusia tidak mengetahui." Dan sekali-kali bukanlah harta dan bukan (pula) anak-anak kamu yang mendekatkan kamu kepada Kami sedikit pun; tetapi orang-orang beriman dan 
mengerjakan amal-amal shaleh, mereka itulah yang memperoleh balasan yang berlipat ganda disebabkan apa yang telah mereka kerjakan, dan mereka aman sentosa di tempat-tempat yang tinggi (dalam surga)." (QS. Saba: 3537). ${ }^{27}$

Maka diakhir tulisan ini penulis berpesan berikanlah kasih sayang pada anak yang membangun. Kasih sayang karena Allah yang akan mendekatkan bukan hanya orang tua, tapi juga sang anak pada Allah.

\section{REFERENSI}

Abdullah Nashih Ulwan. Tarbiyah al-Aulad fi al-Islam, diterjemahkan dengan judul "Pendidikan Anak Dalam Islam.” Jakarta: Pustaka Amani, 2007.

Admin. "Ad Durarus Saniyah - Al Muasu'ah al haditsiyah." Diakses 20 Juni 2019. https://www.dorar.net/hadith/search?

_-_ . "Buah Hati, Antara Perhiasan Dan Ujian Keimanan Almanhaj - Media Salafiyyah Ahlus Sunnah." Diakses 1 Mei 2019. https://almanhaj.or.id/3032-buah-hatiantara-perhiasan-dan-ujian-keimanan.html.

___. "Surat Al-Anfal Ayat 28 Arab, Latin, Terjemahan Arti Bahasa Indonesia." Diakses 21 Maret 2019. https://tafsirweb.com/2894-surat-al-anfal-ayat28.html.

-__. "Surat Saba' Ayat 36." Tafsir AlQuran Online. Diakses 20 Juni 2019.

https://tafsirq.com/permalink/ayat/3642.

27 Admin, “Surat Saba' Ayat 35-37, " Tafsir AlQuran Online, diakses 20 Juni 2019, https://tafsirq.com/permalink/ayat/3642. 
_—_. “Takhrij Hadits Kullukum Ra'in.” Diakses 9 April 2019. https://library.islamweb.net/hadith/hadithServices.php ?type $=1 \&$ cid $=437 \&$ sid $=4967$.

Al Baihaqy. "As Sunanul Kabiir.” Diakses 21 Maret 2019.

http://www.hadithportal.com/index.php?show=hadith \&h_id=19173\&uid=0\&sharh=200000\&all_sharh=full\&bo ok $=49$.

Al Bukhari. "فصل: بَابُ الْوَلَدُ مَبْخَلَةُ حَجْبَةُّانداء الإيمان." Diakses 21 Maret 2019. http://www.al-eman.com

Al Munawi. Faidhul Qadir Syarhul Jamiush Shaghir min

Ahaditsul Basyiri Nadzir Juz 3. Dar Al Kotob Al Ilmiyah, 2018.

At Tirmidzi. Sunan At Tirmidzi hadits no. 2670, t.t.

Ibnu Katsir. "Tafsir Ibnu Katsir.” Diakses 5 April 2019.

http://quran.ksu.edu.sa/tafseer/katheer/sura64aya14.html.

Ibnu Katsir, Get. "Tafsir Surat At-Tahrim, ayat 6-8." Diakses 9 April 2019.

http://www.ibnukatsironline.com/2015/10/tafsirsurat-at-tahrim-ayat-6-8.html.

Ibnu Majah. "Sunan Ibnu Majah, Kitabul Adab Juz 1." Diakses 1 Mei 2019.

https://library.islamweb.net/NewLibrary/display_book. php?bk_no=54\&ID=1406\&idfrom $=6702 \&$ idto=7018\&bo okid=54\&startno=3.

Imam Al Munawi. "Imam Al Munawi, Faidhul Qadir Syarhul Jami'ush shaghir, Juz II hadits nomer 2236.” Diakses 20 Maret 2019. https://books.google.co.id/books

Imam Muslim. Shahih Muslim Hadits no. 1613, t.t. IslamKotob. أدب الدنيا والدين. IslamKotob, t.t.

- - إكمال المعلم بفوائد مسلم - ج 1 . IslamKotob, t.t.

- - . . IslamKotob, t.t. 
Jalaluddin As Suyuti, Yusuf An NAbhani, Muhammad NAshiruddin Al Albani. Tartib Ahadits Shahih Al Jami Ash Shaghir wa ziyadatuhu 'alal abwabil fiqhiyah. Maktabat al-ma"arif, 1986.

Mukhtar Asy Syinqithy. “Tafsir Adhwaul Bayan.” Diakses 5 April 2019.

https://www.islamweb.net/newlibrary/display_book.p hp?idfrom=2726\&idto=2726\&bk_no=64\&ID $=2410$.

"Surat Ali 'Imran Ayat 14 Arab, Latin, Terjemahan Arti Bahasa Indonesia." Diakses 21 Maret 2019.

https://tafsirweb.com/1146-surat-ali-imran-ayat14.html.

"Surat Al-Kahfi Ayat 46 Arab, Latin, Terjemahan Arti Bahasa Indonesia." Diakses 21 Maret 2019.

https://tafsirweb.com/4872-surat-al-kahfi-ayat46.html.

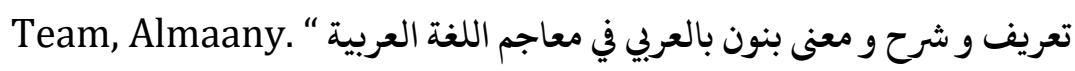

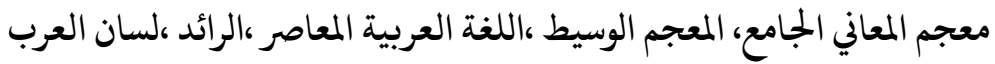

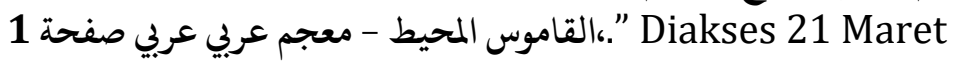
2019. https://www.almaany.com/ar/dict/ar- 